\title{
Exploring the Process of Occupational Adaptation among Novice Lecturers: A Preliminary Case Study
}

\author{
Yu Hong ${ }^{1,2}$, Arnida Abdullah, ${ }^{1, *}$ \\ ${ }^{1}$ Faculty of Educational Studies, Universiti Putra Malaysia, Serdang, 43400, Selangor, Malaysia \\ ${ }^{2}$ School of Educational Science, Guangxi Science \& Technology Normal University, Laibin, 546199, Guangxi, China
}

Received September 26, 2020; Revised December 1, 2020; Accepted December 13, 2020

\begin{abstract}
Cite This Paper in the following Citation Styles
(a): [1] Yu Hong, Arnida Abdullah, "Exploring the Process of Occupational Adaptation among Novice Lecturers: A Preliminary Case Study," Universal Journal of Educational Research, Vol. 8, No. 12B, pp. 8369-8375, 2020. DOI: 10.13189/ujer.2020.082642.
\end{abstract}

(b): Yu Hong, Arnida Abdullah (2020). Exploring the Process of Occupational Adaptation among Novice Lecturers: A Preliminary Case Study. Universal Journal of Educational Research, 8(12B), 8369-8375. DOI: 10.13189/ujer.2020.082642.

Copyright $\odot 2020$ by authors, all rights reserved. Authors agree that this article remains permanently open access under the terms of the Creative Commons Attribution License 4.0 International License

\begin{abstract}
Novice lecturers or also known as neophyte lecturers are an important part of higher education institutions, and the early stages of the career among novice lecturers involve the process of adapting to the new role of educators. They need to overcome different challenges and participate in occupational adaptation. The purpose of this study is to explore the occupational adaptation process among novice lecturers in order to promote their career development. The goal is also to provide useful references for the university management to support novice lecturers in making a successful start in order to grow into professional educators. Using qualitative research method, this study engages case study approach to investigate occupational adaptation process through in-depth interviews of two novice lecturers in a public university in China. By analyzing their emotional and behavioral changes in the process of occupational adaptation, findings indicate that the occupational adaptation process of novice lecturers can be subdivided into three stages; namely 1) initial period, 2) transition period, and 3) adaptation period. The transition and division between each period reveal marked changes mainly in psychological, emotional, and behavioral adjustments. Helping novice lecturers understand the characteristics of the three periods may assist them to adapt to their jobs as soon as possible and accomplish greater success in their careers.
\end{abstract}

Keywords Occupational Adaptation, Process, Novice/Neophyte Lecturers

\section{Introduction}

Novice lecturers or also known as neophyte lecturers are likely to face multiple challenges relating to their pedagogical practices and responsibilities since they are equipped with adequate content knowledge but are lacking in experience and pedagogical skills [1]. For those who have just engaged in their roles and responsibilities as educators, they would need to overcome the challenges of occupational adaptation processes. These adaptation processes would allow them to cope with the occupational demands of their roles and professional development. This is because novice lecturers are those who start their career in the teaching field without having any basic training in teaching [2]. Engaging in the occupational adaptation process allows novice lecturers to maintain effective and efficient performance in their educational institutions. Occupational adaptation is a concept used in occupational therapy to describe the process of interaction between people, their occupations, and their environment in response to occupational challenges [3]. Joanna [4] defines occupational adaptation as a process of adapting newly hired employees to the new conditions of their working environment. She also highlights that although starting a new job in a new environment is a stressful experience, it is also considered as the most important process in their life since they are just beginning their career development. Successful occupational adaptation enables novice lecturers to reach a level of competence in their chosen occupations relevant to their personal life. 


\subsection{Background to the Study}

With the expansion of universities in China, novice lecturers are an important component of teaching staff in higher education institutions, and are the fundamental factors affecting the quality of higher education [5]. The Chinese government has clearly recognized the importance of lecturers and teachers in the development and quality improvement of education. Therefore, Opinions on Improving the Quality of Young Teachers in Higher Education Institutions have been issued to ensure the development of lecturers and teachers. It is suggested that the construction of teaching staff in universities should be further improved from eight factors: ideological and moral level, talent selection and employment system, professional development ability, teamwork, discipline leader construction, institutional environment, working conditions, and organizational leadership. Lecturers' development is not only an important part of education elements but also a key factor affecting the quality of higher education [6]. Most of these novice lecturers have just graduated from university and are full of curiosity and fantasies about the profession of lecturers in China. They are in the period of exploration and discovery of psychological development. Lecturer is a highly specialized occupation, they need advanced professional knowledge, and it is their occupation responsibility to improve their abilities [7]. Teaching is the eternal mission of universities, and lecturers are the core and key to determine the quality of teaching [8]. Teaching quality of novice lecturer is directly relevant to the cultivation of students and university reputation. For that reason, it is meaningful to understand their feelings about occupational adaptation and necessary to help them adapt to their roles more quickly.

\subsection{Literature Review}

Nixon [9] interviewed thirty lecturers from two universities to learn about their views on how they recognize their roles in their occupations. The study found that university lecturers believed that their roles were highly professionalized. Ibrahim, Mohamad, Rom, and Shahrom [10] argued that the work experience of novice lecturers in the early few years has laid the foundation for their professional development and career planning. Murshidi, Konting, Elias and Fooi [11] pointed out that when novice educators enter their first years of teaching, they sometimes face the impact of reality because they know the complexity of teaching responsibilities. That means there is a big gap between the actual work and the ideal. To help novice lecturers adapt to their roles as soon as possible, Turnera, Huang, Poverjuca, and Wyness [12] emphasized the importance of the mentorship. They believe that the one-to-one help from the mentor can make novice lecturer familiar with their work more quickly, and mentors can share valuable experience with them.
In China, most novice lecturers have just received a $\mathrm{PhD}$. or Master's degree. All of them have to make the transition from student to lecturer. Facing the new workplace environment, novice lecturers need to continue learning and improving themselves while completing their job-related responsibilities. The heavy workload and life pressures make it difficult for the lecturers to adapt to their new roles. According to Deng's [13] research, family conditions and personal characteristics of novice educators are the main factors affecting their occupational adaptation status. Jin and Fan [14] took eighty-three novice lecturers from a university in Beijing as a sample. They found that the level of occupational adaptation and professional identity among novice lecturers in this university is generally high, but they will be affected by their age, research field, and overseas study experience. Moreover, there is a significant positive correlation between the professional adaptation and professional identity of these novice lecturers. That means the higher the occupational adaptation, the stronger the professional identity. Lu and Yin [15] used questionnaire survey to explore the mediating effects of novice teachers' occupational adaptation between socioeconomic status and developmental expectation. Their study showed that novice teachers' socioeconomic status and occupational adaptation positively correlated with the developmental expectation. The mediating analysis showed that the mediating effects of novice teachers' occupational adaptation between socioeconomic status and developmental expectation are partially. The achievement of novice teachers' developmental expectation in turn can help to promote occupational adaptation.

Previous studies have concentrated on the occupational adaptation of new employees in companies or primary schools. Many of these researches were among primary school teachers and the main focus was on factors that affect their occupational adaptation and how to improve their teaching skills. Besides, most of these studies employed quantitative approach and data were collected from questionnaire surveys. And some recent studies on lecturers have focused on how to improve professional development, how to promote the development of students, how to cultivate talents and meet the needs for social development. There has not been much study that investigates the occupational adaptation of novice lecturers.

The process of lecturers moving from novices to experts is a lifelong process and the early stage of their career involves the processes of adapting to new roles as pedagogues. According to Schlossberg's transition theory. This is the process from unfamiliar to familiar in a certain situation. This process leads to changes in effects, relationships, and roles. Schlossberg believes that the personal transition period is affected by situation, self, support, and strategy [16]. Situation is the social context in which individuals exist. Self refers to whom it is 
happening to. Support is the help of external conditions for personal development. Strategy is how the individual handles the current issues. In this case study, occupational adaptation process may be the transition of novice lecturers from student to lecturer, from unfamiliarity to proficiency. This theory provides a model for understanding how novice lecturers respond to transitions and how this transition usually affects them. Overall, transition theory is a comprehensive process involving changes that a person has experienced over a long period of time [17].

The purpose of this study, therefore, was to explore and understand the current situation of novice lecturers undergoing the process of occupational adaptation. This study defines occupational adaptation of novice lecturers as a process in which lecturers accept their occupations from their heart, perceive their value, and consciously standardize their careers. Based on the professional development of novice lecturers at Chinese universities, novice lecturer is defined as those lecturers with a permanent, full-time position, least a master's degree and have less than three years of teaching experience. Two specific questions guiding this study are: 1) What is the process of occupational adaptation among novice lecturers in Chinese universities? And, 2) how do novice lecturers adapt to their occupation more quickly?

\section{Methods}

\subsection{Research Design and Sampling}

Babbie [18] states that the outstanding characteristic of qualitative research is to concentrate on the profound study of particular instances or cases of a phenomenon rather than population or samples. A case study is an overall process to understand how people make sense of their lives and their experiences. It is common in educational research. The case study approach is chosen for this study because it provides a detailed understanding of a particular issue [19]. This study was conducted at a public-funded university in Guangxi Province of China. The target population consisted of lecturers employed as university lecturers for a period of not more than three years. For the sample size, Yuan and Lee [20] only interviewed one informant in their study into the emotions and identities of a student-teacher. Baeza [21] also explored the lived experience of one rural teacher in Chile These studies all adopted only one sample size. Based on the nature of qualitative study, the size of the sampling within a case is determined by the study's purpose [22]. For this study, the focus is on the depth of the data, not the breadth, researchers attempt to understand novice lecturer's experiences and stories. Therefore, using typical purposive sampling strategy, two female novice lecturers from different faculties were selected to take part in the interview and assigned pseudonyms, LI MIN and WANG JIN, instead of their real names. Thus, the scope of the study lies in these two novice lecturers' feelings and experiences. However, due to a large number of novice lecturers in Chinese universities, there must be more individualized problems. As a preliminary case study research, the findings are generally limited and may not apply to everyone.

\subsection{Data Collection and Analysis}

The data collection methods for this study were document analysis and in-depth interviews. Documents analysis was conducted to find out the real condition of the lecturer's competence, which can indicate a deeper understanding of the lecturers' profession and characteristics. Another data collection method engaged was semi-structured interviews. Through interviews, the main characteristics and professional attitudes of novice lecturers are obtained. Semi-structured interviews were conducted in the form of face-to-face interviews, which lasted approximately 45 minutes each time. Several semi-structured questions were prepared with the goal to obtain certain required information [23].

By analyzing these first-hand materials, the specific performances of novice lecturers were being reproduced. The researcher tried to present the respondent's occupational adaptation process dynamically. During the interviews, descriptive words and mood words used by respondents in describing their specific experiences may reveal their emotional tendencies. Basically, follow this step to analyze the interview data. Data from the interviews were recorded and transcribed beforehand, narrative analysis of the data was highlighted the situation that evidences the stories and feelings that these two novice lecturers elaborated. Then, the transcripts were sent to informants to check and the narrative was improved by the feedback. To improve the trustworthiness, member-checks and peer review were used to ensure this study is believable.

\section{Research Findings}

\subsection{Initial Period: Why Become a Lecturer}

Cognition, attitude, and insights into one's occupation are important factors that affect the personal choice of an occupation. For novice lecturers, teachers or lecturers are very important for their enlightenment. Because in the process of receiving education from kindergarten to university, teachers and lecturers play an important role in their education. Novice lecturers have a deep understanding and feelings for this job or profession in the process of getting along with teachers and lecturers, they want to be them. On the other hand, some novice lecturers 
already have teaching assistant experience during their $\mathrm{Ph} . \mathrm{D}$. or master's degree studies. They have a preliminary understanding of the role and tasks of the lecturer. As the respondents said:

LI MIN: “...I think university lecturers have relatively free time, and I could use my free time to improve myself professionally ..."

WANG JIN: “...Initially, I wanted to be a university lecturer because I felt that teachers, especially university lecturers, had great freedom, and we could do things we liked when we were not busy. I didn't think so much before I became a lecturer. For example, I didn't expect that there would be a lot of responsibilities, but after I became a lecturer, I felt that the lecturers had many responsibilities. For example, we must set an example for our students. ..."

From the interviews, respondents mentioned "free" when talking about the teaching profession as a lecturer. This indicates that they didn't know much about the duties and responsibilities of lecturer. During this period, therefore, novice lecturers' understanding of the lecturer's role is one-sided. It mainly comes from years of campus life experiences and the perceptions of daily life.

When talking about the motivation of being a lecturer, the respondents gave their own views:

LI MIN: “...Actually, I didn't decide to choose the lecturer as my career. It seems that I have naturally become a lecturer among different choices. Maybe because I like reading books, learning knowledge, and live on campus. I feel that the atmosphere of the university campus is good for me, so I chose to be a lecturer at a university. ..."

WANG JIN: “...I also tried to find a job when I graduated with a master's degree. I found a higher paid job in Guangzhou. However, I feel that the research work may be suitable for me and I still want to teach in a university, so I continued to study for my Ph.D. and found a job as a lecturer here. ..."

Based on the analysis, it is not difficult to find that the attraction of the work environment and the pursuit of personal life prompted them to choose the occupation of university lecturers when they finally made choices. Moreover, the freedom of the occupation, and the individual's interests and hobbies are also one of the factors that they consider when choosing the job.

\subsection{Transition Period: Understand and Try to Adapt to the New Role}

At this stage, novice lecturers actively take measures to create a comprehensive career development plan and they have adjusted and adapted to the occupation of lecturers so well. In addition, novice lecturers have a deeper understanding of the job duties, rights, responsibilities, and roles of lecturers. They have recognized that lecturers are not only teaching but also entails other roles such as scientific researchers and student development tutors. Through the accumulation of class experiences and self-reflection, their productivity and work performance has improved.

LI MIN: "...When I first came to the platform. I thought I was so well prepared, but why students can't focus on the lecture. I felt very confused at the beginning, and later I communicated with other experienced lecturers, and have an understanding. I can't ask all students to like my lecture. I don't require every student to listen to me, that is to say, for example, if there are 10 students who have not to focus on study in this lecture, maybe I could try to reduce to 8 or 9 students in the next lecture. As long as the students' attention is focused, I think I have made progress in the preparation and teaching. ..."

“...It is worthwhile to get the recognition of students. I will continue even if only one student recognizes me. If more students can recognize, I think that is the happiest thing for me. ..."

According to LI MIN, the value of lecturers' occupation is not the material reward but the growth and progress of students. The source of occupational happiness is student recognition and acceptance. What is more emphasized is the social value of the lecturers' occupation.

WANG JIN: “...With the familiarity of teaching documents and lectures, the focus of stress has transferred. The stress or pressure faced in the first year of teaching comes from the tension of the classroom teaching and the interaction of students. But after one or two years of work, the stress will be overcome, I could basically control the classroom atmosphere now, and I am more familiar with it than before, so I should say that I enjoy the classroom now. But at the same time a new pressure is coming, that is, whether my teaching can meet the needs of students, whether I can help students improve their scores and whether I can improve the quality of teaching. ..."

The process of role adaptation is complex and procedural. It is a process of continuous mutual adaptation between the individuals and the environment [24]. For novice lecturers, in order to make a smooth transition, they must actively adjust themselves and form correct self-cognition.

\subsection{Adaptation Period: Be Proud of Being a Lecturer}

Strong occupational values play an important role in the process of occupational adaptation among novice lecturers. The accumulation of emotions and experiences in the early period has sublimated the occupational emotions of 
novice lecturers.

LI MIN: "...There is no worry about the effect of the classroom lecture. After all, I have been working for several years, and I have accumulated a lot of teaching experience. What feels most stressful now is how to improve myself, maybe it's almost a burnout period. Now the main thing I want to do is how to break through this dilemma and have more vitality. Otherwise, I will get tired...."

During this period, novice lecturers have been able to fully adapt to their roles and able to switch between different roles as well. They have been able to distinguish the gap between ideals and reality, adapt to the working environment and intensity of the lecturers' occupation, and be able to respond proficiently.

When asked whether novice lecturers were willing to transfer to administrative work or choose a new occupation, the respondents stated that if they were re-selected, they would still choose to become a university lecturer, and tend to continue their current work without considering administrative work. It can be seen that novice lecturers have a strong tendency to adhere to the teaching profession.

LI MIN: “...I should not be thinking about leaving now. Because I regard being a lecturer here as a lifelong goal and career, I may not consider changing it. ..."

WANG JIN: “...I am very enthusiastic about this job and willing to stand on the platform and communicate with students. When I stand on the platform, I feel happy. Maybe I didn't have breakfast this morning, didn't sleep well last night, or something happened at home. But when I stand on the platform, I will forget all these things. I don't think it's an escape, it's just an investment. So, this kind of enthusiasm makes me reluctant to leave here. I am willing to make my contribution here. ..."

It can be seen that novice lecturers have become passionate about the occupation of lecturers after going through the first two periods. They believe that the profession of lecturers can bring great satisfaction and happiness to themselves. Therefore, they are more committed to doing this job well.

\section{Conclusions}

\subsection{There are Three Different Periods in the Process of Occupational Adaptation among Novice Lecturers}

Individual's occupation attitudes, occupation requirements, and occupation choice intentions have already existed in childhood [25]. Based on these findings, the researcher found that with the improvement of education, the enrichment of life experience, occupational psychology of different individuals will also change. Therefore, it can be concluded that there are different periods in the occupational adaptation of novice lecturers, which is a slow development process. This process can be divided into three stages: initial period, transition period, and adaptation period.

For these novice lecturers in the initial period, they have insufficient knowledge of the occupation of lecturers, and their occupation expectations are too idealistic. Due to the lack of comprehensive knowledge of occupation in the early period and the high occupation expectations, novice lecturers will be greatly affected when they carry out practical work in the university, resulting in professional anxiety and pressure. In order to adapt to the lecturer's occupation as soon as possible and reduce the impact of role conflicts, novice lecturers actively seek organizational support and self-adjustment. With the help of colleagues and the accumulation of successful teaching experience, novice lecturers' occupation cognition has gradually become clear, teaching efficacy and teaching confidence have risen, and lecturers' occupation adaptation has continued to improve. They begin to associate lecturers' careers with their own life values and to regard lecturers as lifelong careers.

In summary, the occupation adaptation of novice lecturers is a gradual process. This development process cannot be accomplished overnight, nor can it be smooth. The development of lecturers' occupation adaptation not only requires individuals to improve their professional ability and strengthen their psychological quality but also needs support and help from university and society. In addition, novice lecturers' occupation adaptation has different periods, but there is no obvious time mark between each period. The transition and division between the three periods are mainly marked by changes in the novice lecturers' psychology, emotions, and behaviors.

\section{Suggestions}

During the process of occupational adaptation, novice lecturers could take the initiative, play their initiative, and strive to achieve occupational adaptation. First of all, novice lecturers should have a correct and profound understanding of themselves. They need to evaluate themselves realistically, objectively recognize their ability level, strengths, and weaknesses. They also should set realistic and operational career goals based on their reality, and make career planning in advance [26]. Besides, they should have a correct understanding of the social expectations of lecturers, and fully understand the role of lecturers. At the same time, they need to relieve the stress and strive to transform the external constraints into their internal career pursuit and motivation, so as to maintain healthy occupational psychology.

Secondly, novice lecturers should learn professional knowledge, establish a good knowledge structure, 
improve psychological quality, and enhance professional ability. In daily work and study, they need to pay attention to the accumulation of teaching experience and take the initiative to ask other experienced lecturers for advice. Only in this way can they have confidence and ability to do a good job in teaching and scientific research, establish a friendly and harmonious relationship between themselves and students.

\section{Acknowledgments}

The author would like to thank all the participants in this study as well as Guangxi Science and Technology Normal University.

\section{REFERENCES}

[1] Remmik M, Karm M, Haamer A, \& Lepp L, "Early-career Academics' Learning in Academic Communities," International Journal for Academic Development, vol. 16, no. 3, pp. 187-199, 2011. DOI: 10.1080/1360144X.2011.59 6702 .

[2] Nicholls G, "New Lecturers' Constructions of Learning, Teaching, and Research in Higher Education," Studies in Higher Education, vol. 30, no. 5, pp. 611-625, 2005. DOI: $10.1080 / 03075070500249328$.

[3] Grajo L, Boisselle A, \& DaLomba E, "Occupational Adaptation as a Construct: A Scoping Review of Literature," The Open Journal of Occupational Therapy, vol. 6, no. 1, pp. 1-28, 2018. DOI: 10.15453/2168-6408.1400.

[4] Joanna G, "Professional Adaptation of New Employees to The Organization," System Safety:Human-Technical-Facili ty-Environment, vol. 1, no. 1, pp. 929-938, 2019. DOI: 10.2478/czoto-2019-0118.

[5] Zhou T. "Research on Teaching Professional Development of New Faculty Members of Higher Education in China." (Unpublished master's thesis). Shenyang Normal University, Shenyang, 2013.

[6] Sumarsono, P. "Professional development for novice EFL lecturers: Policy and practices at University of Muhammadiyah Malang." In International Conference on Teacher Training and Education. Sebelas Maret University, Surakarta. pp. 780-787, 2015.

[7] Mwanza-Kabaghe S., and Mofu-Mwansa M. "Lecturers experiences, challenges and prospects on continuing professional development." The Namibia CPD Journal for Educators, vol. 4, no. 1, pp. 88-105, 2018. DOI: 10.32642/ncpdje.vi.1301.

[8] Mahmud A B, Alwi N H B, \& Sulaiman T B. "A Qualitative Study on the Perspective and Teaching Practice of Novice Lecturers in a Paramedic Course." Education in Medicine Journal, vol. 6, no. 1, pp. 45-49, 2014, DOI: 10.5959/eimj. v6i1.194.

[9] Nixon J, "Professional Identity and The Restructuring of Higher Education," Studies in Higher Education, vol. 21, no.
1, pp. 5-16, 1996. DOI: 10.1080/03075079612331381417.

[10] Ibrahim A B, Mohamad F, Rom K B M, \& Shahrom S M. "Identifying Strategies Adopted by Novice Lecturers in the Initial Years of Teaching." Procedia-Social and Behavioral Sciences, no. 90, pp. 3-12, 2013. DOI: 10.1016/j.sbspro.201 3.07.059.

[11] Murshidi R, Konting M M, Elias H, \& Fooi F S. "Sense of Efficacy among Beginning Teachers in Sarawak." Teaching Education, vol. 17, no. 3, pp. 265-275, 2006, DOI: $10.1080 / 10476210600849730$.

[12] Turner R, Huang R, Poverjuc O \& Wyness L, "What role do Teaching Mentors Play in Supporting New University Lecturers to Develop Their Teaching Practices?" Professional Development in Education, vol. 42, no. 4, pp. 647-665, 2016, DOI: 10.1080/19415257.2015.1065898.

[13] Deng Y H, "Research on the Influencing Factors of New Elementary School Teachers' Employment Adaptation." Journal of the Chinese Society of Education, no. 11, pp. 65-68, 2011.

[14] Jin M Z, Fan F M, "Research on the Occupational Adaptation and Professional Identity of university novice faculty", Tsinghua Journal of Education, vol. 38, no. 3, pp. 113-117, 2017.

[15] Lu Q C, Yin Y X, “The Research on the Relation between Socioeconomic Status and Developmental Expectation: Take Occupational Adaptation as Mediating Variable", Journal of Schooling Studies, vol. 13, no. 5, pp. 80-90, 2016.

[16] Schlossberg N K, "The Challenge of Change: The Transition Model and Its Applications," Journal of Employment Counseling, vol. 48, no. 4, pp. 159-162, 2011. DOI: 10.1002/j.2161-1920. 2011.tb01102. x.

[17] Anderson M L, Goodman G, \& Schlossberg N K, "The Transition Framework" in Counseling Adults in Transition: Linking Schlossberg's Theory with Practice in a Diverse World, 4th ed, Springer Publishing Company, 2012.

[18] Babbie E, "Modes of observation in Observing Ourselves: Essays in Social Research.” 2nd ed, Waveland Press, 2015.

[19] Lichtman M, "Qualitative Research Approaches" in Understanding and Evaluating Qualitative Educational Research, Sage Publications, 2010.

[20] Yuan R, Lee I. "'I need to be strong and competent': A Narrative Inquiry of a Student-Teacher's Emotions and Identities in Teaching Practicum." Teachers and Teaching, vol. 22, no. 7, pp. 819-841, 2016. DOI: $10.1080 / 13540602.2016 .1185819$.

[21] Baeza A R. "Exploring the Lived Experience of One Rural Teacher in Indigenous Context in Chilean Northern Territory: A Narrative Inquiry." International Journal of Critical Indigenous Studies, vol. 12, no. 1, pp. 29-45, 2019. DOI: $10.5204 /$ ijcis. v11i1.1100.

[22] Yin R K. "Case Study Research and Applications: Design and Methods." 6th ed. California: Sage publications. Inc, 2018.

[23] Merriam S B, \& Tisdell E J. "Qualitative Research: A Guide to Design and Implementation." 4th ed. San Francisco: John Wiley \& Sons, 2016. 
[24] Adom, D., Essel, H. B., \& Chukwuere, J. "The State of Academic Stress in the Higher Institutions of Ghana: The Way Forward". Universal Journal of Educational Research, vol. 8, no. 2, pp. 321-331. 2020. DOI: 10.13189/ujer.2020.0 80201.

[25] Ma H Y, “A Study on Teacher's Professional Identity of the University of A," (Unpublished master's thesis). Hebei University, Shijiazhuang, 2019.
[26] Meng L H, “A Study on The Process of Professional Identity of Young Teachers in Universities: Based on Eight Young Teachers in Beijing Universities," (Unpublished master's thesis). China Youth University of Political Studies, Beijing, 2018. 